\title{
Enhanced Vasopressin Release upon Activation of the Central Neural Mechanism in Spontaneously Hypertensive Rats
}

\author{
Masatsugu NaKaI, Yoko Yamane, ${ }^{*}$ Yukihisa UmEda, ${ }^{*}$ \\ Jin Yамамото, and Yukio Matsui** \\ Department of Cardiovascular Dynamics, National \\ Cardiovascular Center, Suita, 565 Japan \\ * Department of Internal Medicine, Kansai Medical University, \\ Moriguchi, 570 Japan \\ ** Department of Internal Medicine, Saga Medical University, \\ Saga, 840-01 Japan
}

\begin{abstract}
Summary Monopolar electrical stimulation of the intermediate portion of the solitary nucleus in spontaneously hypertensive rats (SHRs) with cervical cordotomy and vagotomy resulted in a 1.68 times greater increase in plasma vasopressin concentration than in Wistar rats. The result implies that such an enhanced function of the central neural mechanism to release vasopressin in SHR backs up the functionally aberrant cardiovascular receptors.
\end{abstract}

Key words: spontaneously hypertensive rats, solitary nucleus, plasma vasopressin.

Although a very small but significant difference in plasma vasopressin concentration (PVP) is often reported between spontaneously hypertensive rats (SHRs) and normotensive rats, the PVP in the resting state was found to be maintained at substantially normal levels in SHRs as in normotensive rats (e.g. RASCHER et al., 1982; RocKHOLD et al., 1984). It is conceivable therefore that the overall function of the cardiovascular reflex mechanisms which tonically regulate vasopressin release, operates normally. On the other hand, it is an established fact that the baroreceptors are aberrant in SHRs (BROWN, 1980). A reduced sensitivity of carotid chemoreceptors has also been suggested in SHRs (PRZYBYLSKI, 1981).

Such findings inevitably raise the question of whether or not the central neural mechanism, which regulates vasopressin release and upon which the terminals of afferents of the receptor mechanisms about, backs up the functionally aberrant

Received for publication February 3, 1986 
cardiovascular receptors so that the overall function of the reflex mechanisms remains normal. The present study was undertaken therefore to assess the neurosecretory function of the central neural mechanism for releasing vasopressin in SHRs. In an attempt to activate such a neural mechanism, we electrically stimulated the intermediate portion of the solitary nucleus upon which afferents of the cardiovascular reflexes are known to terminate (PALKOviTs and ZABORSZKY, 1977; SPYER, 1981). The stimulation is reported to elicit a consistent increase in PVP (YAMANE et al., 1984; NAKAI et al., 1985).

Experiments were conducted during the day on 19 male SHRs and 25 male normotensive Wistar rats, aged 13 to 15 weeks. Details of the experimental procedure have been given in a previous paper (NAKAI et al., 1985). Thin polyethylene cannulae were introduced into the femoral arteries and veins bilaterally under $2 \%$ halothane anesthesia. The animals were then artificially ventilated, immobilized with $d$-tubocurarine $(0.5 \mathrm{mg} / \mathrm{kg}$ body weight, i.m. ) and maintained in a homeothermic state. The bilateral vago-sympathetic trunks were cut. At this stage of the experiments, the baseline arterial blood pressure and heart rate of each rat were monitored at the end of a settling period of 30 min under $60 \% \mathrm{~N}_{2} \mathrm{O}$ anesthesia. Cordotomy was then performed at $\mathrm{C}_{2}$ on a stereotaxic frame under a second session of halothane anesthesia. The autonomic outflow to the systemic circulation was thus entirely eliminated and the experiment could be carried out under a stable arterial blood pressure upon stimulation of the solitary nucleus. Continuous infusion of phenylephrine via a venous catheter served to combat hypotension. The degree of blood loss during surgery was estimated by weighing the cotton pellets which had absorbed the shed blood. The animals were then replenished with an appropriate amount of blood obtained from outbred rats. On termination of the operative procedures, the anesthetic was again switched to $60 \% \mathrm{~N}_{2} \mathrm{O}$.

During a subsequent 60 -min settling period, cross circulation for sampling of $1.4 \mathrm{ml}$ of arterial blood over $2 \mathrm{~min}$ for determination of the PVP was set up with another anesthetized (Nembutal, $40 \mathrm{mg} / \mathrm{kg}$, i.p.) donor rat (Wistar rat). This procedure allowed repetitive sampling of blood to be carried out without producing hypovolemia in the SHRs (NAKAI et al., 1985).

The monopolar electrode for stimulation consisted of an insulated stainless steel wire $(0.15 \mathrm{~mm}$ in diameter) with only the bevelled tip exposed. An indifferent electrode (chlorided silver plate) was embedded in the muscles of the back. The electrode was lowered with a micromanipulator into the solitary nucleus and was fixed in place where the vasopressin-induced pressor response (NAKAI et al., 1982, 1985; YAMANE et al., 1984) was elicited with the lowest threshold current of stimulus. Arterial blood was then sampled for determination of the control PVP. Beginning $2 \mathrm{~min}$ before the start of the second sampling, the solitary nucleus was stimulated (NAKAI et al., 1985) with intermittent ( $1 \mathrm{~s} \mathrm{on} / 1 \mathrm{~s}$ off) trains of pulses $(50 \mathrm{~Hz} ; 0.5 \mathrm{~ms}$ width) over $4 \mathrm{~min}$. During this period of stimulation, the phenylephrine infusion was reduced in rate or discontinued so that the marked vasopressininduced pressor response was minimal. Otherwise, considerable bleeding would 
Table 1. Body weight, hemodynamic parameters, arterial blood gas values, phenylephrine $(\mathrm{PE})$ infusion rate $\left(\mathrm{ng} \cdot \mathrm{min}^{-1} \cdot(100 \mathrm{~g} \text { body weight })^{-1}\right)$, and control plasma vasopressin concentration (PVP, $\mathrm{pg} / \mathrm{ml}$ ).

\begin{tabular}{llcc}
\hline & & Wistar rats & SHRs \\
\hline Number of animals & & 25 & 19 \\
Body weight $(\mathrm{g})$ & $389 \pm 7$ & $297 \pm 5^{* * *}$ \\
Threshold $(\mu \mathrm{A})$ & $9.6 \pm 0.7$ & $6.6 \pm 0.7^{* * *}$ \\
Blood pressure $(\mathrm{mmHg})$ & Control & $123 \pm 2$ & $182 \pm 3^{* * *}$ \\
& Stimulation & $141 \pm 3^{+\dagger \dagger}$ & $200 \pm 3^{* * *+\dagger \dagger}$ \\
Heart rate (beats/min) & Control & $376 \pm 5$ & $388 \pm 8^{\text {ns }}$ \\
& Stimulation & $351 \pm 5^{\dagger \dagger \dagger}$ & $373 \pm 9^{*, \dagger}$ \\
PE infusion rate (iv) & Control & $178 \pm 23$ & $184 \pm 35^{\text {ns }}$ \\
& Stimulation & $15 \pm 9^{\dagger+\dagger}$ & $0 \pm 0^{* * *+\dagger \dagger}$ \\
Control PVP & & $20.5 \pm 2.5$ & $29.3 \pm 3^{*}$ \\
\hline
\end{tabular}

Data are presented as mean \pm S.E. ${ }^{*}$ The difference from the Wistar rats was significant ( $p<0.05$, unpaired $t$-test $) ;{ }^{* * *} p<0.001 ;{ }^{\text {ns }}$ not significant $(p>0.05) .{ }^{\dagger}$ The difference from the control was sginificant $\left(p<0.05\right.$, paired $t$-test); ${ }^{\dagger \dagger} p<0.001$.

have taken place. The PVP was measured according to the radioimmunoassay technique proposed by HuSAIN et al. (1973). The vasopressin antiserum was a kind gift from Dr. T. Saito, Jichi Medical College, Tochigi, Japan. Data from the rats were abandoned when the control PVP exceeded a level of $50 \mathrm{pg} / \mathrm{ml}$.

The baseline mean arterial pressure observed before cordotomy (data not shown) was approximated well by the control pressure (Table 1) which was set artificially by adjusting the phenylephrine infusion after cordotomy and observed shortly before stimulation of the solitary nucleus. The pressure during stimulation was moderately elevated, despite the phenylephrine infusion being reduced in rate or discontinued. It was found that the threshold current, which increased the mean arterial pressure by $10 \mathrm{mmHg}$, was significantly lower in the SHRs. In both the SHRs and Wistar rats, the control PVP was considerably higher than reported previously (e.g. RASCHER et al., 1982; ROCKHOLD et al., 1984), in spite of the replenishment of blood. Figure 1 shows the stimulation-evoked increase in PVP in Wistar rats and in SHRs. At a stimulus intensity of $50 \mu \mathrm{A}$, the PVP in the SHRs was found to be increased to a 1.68 times higher level than in the Wistar rats. We conclude therefore that the central neural mechanism which emanates from the solitary nucleus possesses an enhanced sensitivity for regulating vasopressin release in SHR.

Our study to observe the changes in PVP upon stimulation of the solitary nucleus was performed under a different phenylephrine infusion rate and arterial blood pressure from those in the control study (Table 1). These differences themselves might modify the degree of vasopressin release (SHARE, 1976; SCHRIER et al., 1979; BRUNNER et al., 1983) upon stimulation. In a previous paper (NAKAl et al., 


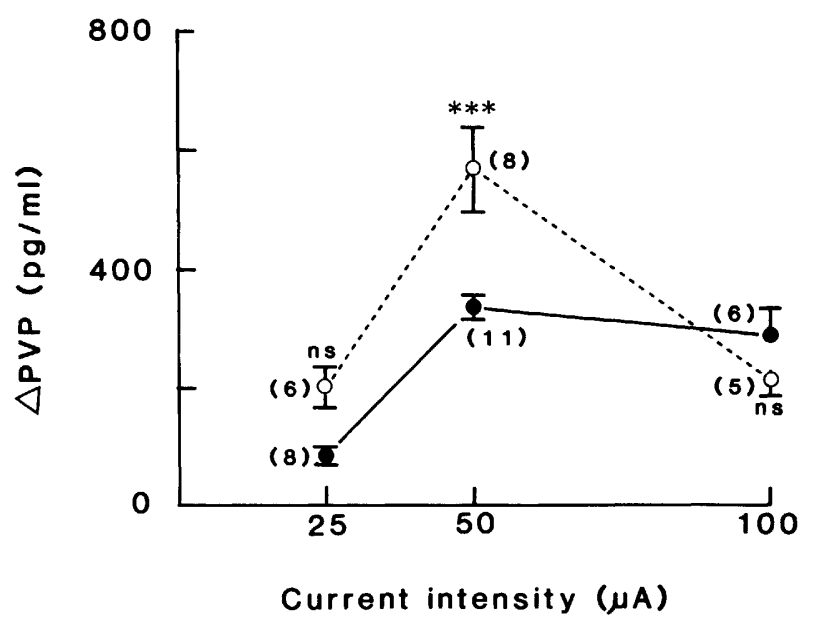

Fig. 1. Increase in plasma vasopressin concentration ( $\triangle P V P$; mean \pm S.E.) upon electrical stimulation of the intermediate portion of the solitary nucleus in normotensive Wistar rats (solid lines with closed circles) and in age-matched SHRs (broken lines with open circles). Numerals in parentheses indicate the number of animals. ${ }^{* * *}$ The difference from the Wistar rats was significant $(p<0.001$, two-way analysis of variance); ns not significant $(p<0.05)$.

al., 1985), however, we demonstrated that with our experimental setup, modification of the increase in vasopressin release upon stimulation was not detected regardless of the rate of phenylephrine infusion or level of blood pressure.

Although the blood loss at the time of surgery was compensated by blood transfusion, the control PVP observed shortly before stimulation of the solitary nucleus was very high. Such a high control PVP may be accounted for by the surgery, artificial ventilation, and sectioning of the vagus and aortic nerves. The high PVP itself might then modulate the degree of increase in PVP upon stimulation through some negative feedback mechanism (SKLAR and SCHRIER, 1983). However, the high control PVP may not invalidate our data since the averaged control PVP values obtained in Wistar rats and in SHRs were at the same general level as each other. In the present report, we found a lower threshold current in SHRs than in Wistar rats. This result, however, may not imply an enhanced sensitivity of central neural mechanism to release vasopressin in SHRs, since the arteries of SHRs are known to possess an enhanced responsiveness to vasopressin (SUETA et al., 1983).

It is an established fact that the optimum work range of cardiovascular receptors of SHRs is reset towards a higher blood pressure level in atrial stretch receptors (THOREN et al., 1979) and in arterial baroreceptors (BROWN, 1980). In addition to resetting, the arterial baroreceptors, which inhibitorily regulate vasopressin release (SHARE, 1976; SCHRIER et al., 1979), are known to possess a reduced sensitivity to a change in pressure in SHRs when compared with that of normotensive control rats (Brown et al., 1976; SAPRU and WANG, 1976; ANDRESEN et al., 
1980). It is conceivable therefore that such reduced sensitivity of the baroreceptors in SHRs could lead to less sufficient disinhibition of vasopressin release upon hypotension than in normotensive rats. The carotid chemoreceptors, whose activation increases vasopressin release (SHARE and LEVY, 1966), have also been suggested to be less sensitive in SHRs (PrZYBYLSKI, 1981). Stimulation of the chemoreceptors in SHRs would then fail to adequately raise plasma vasopressin concentration. However, it was reported in SHR (RockHOLD et al., 1984) that an exaggerated response of vasopressin release resulted from hemorrhagic hypotension down to such a low level that the chemoreceptors would be amply stimulated (EYZAGUIRRE et al., 1983) together with a suppression of the baroreceptor activity. Further, despite such aberrant function of the cardiovascular receptors, the PVP in the resting state was found to be maintained more or less within the normal range in SHRs as in normotensive rats (e.g. RASCHER et al., 1982; RoCKHOLD et al., 1984).

To reconcile these conflicting findings, it may be logical to assume as follows: (a) the central ascending neural mechanism which emanates from the solitary nucleus and upon which the terminals of the afferents of the cardiovascular receptors terminate (PALKOvITS and ZABORSZKY, 1977; SPYER, 1981), possesses an enhanced sensitivity for regulating vasopressin release in SHR; (b) the central neural mechanism may then back up the reduced sensitivity of the cardiovascular receptors; (c) thus, the overall function of the entire cardiovascular reflex mechanisms may operate adequately in the resting state, and even hyperactively upon hemorrhagic hypotension.

\section{REFERENCES}

Andresen, M. C., Kuraoka, S., and Brown, A. M. (1980) Baroreceptor function and changes in strain sensitivity in normotensive and spontaneously hypertensive rats. Circ. Res., 47: 821-828.

Brown, A. M. (1980) Receptors under pressure: An update on baroreceptors. Circ. Res., 46: $1-10$.

Brown, A. M., SAUm, W. R., and Tuley, F. H. (1976) A comparison of aortic baroreceptor discharge in normotensive and spontaneously hypertensive rats. Circ. Res., 39: 488-496.

Brunner, D. B., Burnier, M., and Brunner, H. R. (1983) Plasma vasopressin in rats: Effect of sodium, angiotensin, and catecholamines. Am. J. Physiol., 244: H259-H265.

Eyzaguirre, C., Fitzgerald, R. S., Lahiri, S., and Zapata, P. (1983) Arterial chemoreceptors. In: Handbook of Physiology, ed. by Shepherd, J. T., AbBoud, F. M., and Geiger, S. R., American Physiological Society, Maryland, Vol. III, Sect. 2, pp. 557-621.

Husain, M. K., Fernando, N., Shapiro, M., Kagan, A., and Glick, S. M. (1973) Radioimmunoassay of arginine vasopressin in human plasma. J. Clin. Endocrinol. Metabol., 37: 616-625.

NakaI, M., Yamane, Y., Umeda, Y., and Ogino, K. (1982) Vasopressin-induced pressor response elicited by electrical stimulation of solitary nucleus and dorsal motor nucleus of vagus of rat. Brain Res., 251: 164-168. 
Nakai, M., Yamane, Y., Umeda, Y., Yamamoto, J., and Ogino, K. (1985) Approach for quantifying the overall function of the ascending central neural integration to release vasopressin in rats. Jpn. J. Physiol., 35: 887-901.

PALKovits, M. and ZABORSZKY, L. (1977) Neuroanatomy of central cardiovascular control. Nucleus tractus solitarii: Afferent and efferent neuronal connections in relation to the baroreceptor reflex arc. Prog. Brain Res., 47: 9-34.

PRZYBYLSKI, J. (1981) Do arterial chemoreceptors play a role in the pathogenesis of hypertension? Med. Hypotheses, 7: 127-131.

Rascher, W., Lang, R. E., Unger, T., Ganten, D., and Gross, F. (1982) Vasopressin in brain of spontaneously hypertensive rats. Am. J. Physiol., 242: H496-H499.

Rockhold, R. W., Crofton, J. T., Brooks, D. P., and Share, L. (1984) The response of vasopressin and blood pressure to hemorrhage in SHR and WKY rats. Clin. Exp. Hypertens., A6: 827-849.

SAPRU, H. N. and WANG, S. C. (1976) Modification of aortic baroceptor resetting in the spontaneously hypertensive rat. Am. J. Physiol., 230: 664-674.

SCHRIER, R. W., BERL, T., and ANDERSON, R. J. (1979) Osmotic and nonosmotic control of vasopressin release. Am. J. Physiol., 236: F321-F332.

SHARE, L. (1976) Role of cardiovascular receptors in the control of ADH release. Cardiology, 61: 51-64.

Share, L., and LeVY, M. N. (1966) Effect of carotid chemoreceptor stimulation on plasma antidiuretic hormone titer. Am. J. Physiol., 210: 157-161.

SKLAR, A. H. and SCHRIER, R. W. (1983) Central nervous system mediators of vasopressin release. Physiol. Rev., 63: 1243-1280.

SPYER, K. M. (1981) Nueral organization and control of the baroreceptor reflex. Rev. Physiol. Biochem. Pharmacol., 88: 23-124.

Sueta, C. A., Hutchins, P. M., and Dusseau, J. W. (1983) Norepinephrine-induced potentiation of arginine vasopressin reactivity in arterioles of the spontaneously hypertensive rat. Hypertension, 5: 321-327.

Thoren, P., Noresson, E., and Ricksten, S. -E. (1979) Resetting of cardiac C-fiber endings in the spontaneously hypertensive rat. Acta Physiol. Scand., 107: 13-18.

Yamane, Y., NaKaI, M., Yamamoto, J., Umeda, Y., and Ogino, K. (1984) Release of vasopressin by electrical stimulation of intermediate portion of the nucleus of the tractus solitarius in rats with cervical spinal cordotomy and vagotomy. Brain Res., 324: $358-360$. 